\title{
RESIDUAL QUOTIENT AND ANNIHILATOR OF INTUITIONISTIC FUZZY SETS OF RING AND MODULE
}

\author{
P.K. Sharma ${ }^{1}$ and Gagandeep Kaur ${ }^{2}$ \\ ${ }^{1}$ P.G. Department of Mathematics, D.A.V. College, Jalandhar City, Punjab, India \\ ${ }^{2}$ Research Scholar, IKG PT University, Jalandhar, Punjab
}

\begin{abstract}
In this paper, we introduce the concept of residual quotient of intuitionistic fuzzy subsets of ring and module and then define the notion of residual quotient intuitionistic fuzzy submodules, residual quotient intuitionistic fuzzy ideals. We study many properties of residual quotient relating to union, intersection, sum of intuitionistic fuzzy submodules (ideals). Using the concept of residual quotient, we investigate some important characterization of intuitionistic fuzzy annihilator of subsets of ring and module. We also study intuitionistic fuzzy prime submodules with the help of intuitionistic fuzzy annihilators. Many related properties are defined and discussed.
\end{abstract}

\section{KEYWORDS}

Intuitionistic fuzzy (prime) submodule (ideal), residual quotient intuitionistic fuzzy submodules (ideal), intuitionistic fuzzy annihilator, semiprime ring.

\section{INTRODUCTION}

The concept of intuitionistic fuzzy sets was introduced by Atanassov [1], [2] as a generalization to the notion of fuzzy sets given by Zedah [16]. Biswas was the first to introduce the intuitionistic fuzzification of the algebraic structure and developed the concept of intuitionistic fuzzy subgroup of a group in [5]. Hur and others in [8] defined and studied intuitionistic fuzzy subrings and ideals of a ring. In [7] Davvaz et al. introduced the notion of intuitionistic fuzzy submodules which was further studied by many mathematicians (see [4], [9], [12], [13], [14]).

The correspondence between certain ideals and submodules arising from annihilation plays a vital role in the decomposition theory and Goldie like structures (see [6]). A detailed study of the fuzzification of this and related concepts can be found in [10], [11] and [15]. Intuitionistic fuzzification of such crisp sets leads us to structures that can be termed as intuitionistic fuzzy prime submodules. In this paper, we attempt to define annihilator of an intuitionistic fuzzy subset of a module using the concept of residual quotients and investigate various characteristic of it. This concept will help us to explore and investigate various facts about the intuitionistic fuzzy aspects of associated primes, Godlie like structures and singular ideals.

\section{Preliminaries}

Throughout this section, $\mathrm{R}$ is a commutative ring with unity $1,1 \neq 0, \mathrm{M}$ is a unitary $\mathrm{R}$-module and $\theta$ is the zero element of M. The class of intuitionistic fuzzy subsets of $X$ is denoted by IFS(X).

\section{Definition (2.1)[4]}

Let $\mathrm{R}$ be a ring. Then $\mathrm{A} \in \mathrm{IFS}(\mathrm{R})$ is called an intuitionistic fuzzy ideal of $\mathrm{R}$ if for all $x, y \in \mathrm{R}$ it satisfies 
International Journal of Computer Science \& Information Technology (IJCSIT) Vol 9, No 4, August 2017

(i) $\mu_{A}(x-y) \geq \mu_{A}(x) \wedge \mu_{A}(y), v_{A}(x-y) \leq v_{A}(x) \vee v_{A}(y)$

(ii) $\mu_{A}(x y) \geq \mu_{A}(x) \vee \mu_{A}(y) \quad, \quad v_{A}(x y) \leq v_{A}(x) \wedge v_{A}(y)$.

The class of intuitionistic fuzzy ideals of $\mathrm{R}$ is denoted by IFI(R).

\section{Definition (2.2)[4]}

An intuitionistic fuzzy set $\mathrm{A}$ of an R-module $\mathrm{M}$ is called an intuitionistic fuzzy submodule (IFSM) if for all $x, y \in \mathrm{M}$ and $r \in \mathrm{R}$, we have

(i) $\mu_{A}(\theta)=1, v_{A}(\theta)=0$

(ii) $\mu_{A}(x+y) \geq \mu_{A}(x) \wedge \mu_{A}(y), \quad v_{A}(x+y) \leq v_{A}(x) \vee v_{A}(y)$;

(iii) $\mu_{A}(r x) \geq \mu_{A}(x), \quad v_{A}(r x) \leq v_{A}(x)$.

The class of intuitionistic fuzzy submodules of M is denoted by IFM(M).

\section{Definition $(2.3)[2,12]$}

Let $\alpha, \beta \in[0,1]$ with $\alpha+\beta \leq 1$. An intuitionistic fuzzy point, written as $x_{(\alpha, \beta)}$, is defined to be an intuitionistic fuzzy subset of $X$, given by

$x_{(\alpha, \beta)}(y)=\left\{\begin{array}{cc}(\alpha, \beta) & \text {; if } y=x \\ (0,1) & \text {; if } y \neq x\end{array}\right.$. We write $x_{(\alpha, \beta)} \in A$ if and only if $x \in C_{(\alpha, \beta)}(A)$,

where $C_{(\alpha, \beta)}(A)=\left\{x \in X: \mu_{A}(x) \geq \alpha\right.$ and $\left.\nu_{A}(x) \leq \beta\right\}$ is the $(\alpha, \beta)-c u t$ set (crisp set)

of the intuitionistic fuzzy set $\mathrm{A}$ in $\mathrm{X}$.

\section{Definition (2.4)[9]}

Let $\mathrm{M}$ be an R-module and let $\mathrm{A}, \mathrm{B} \in \operatorname{IFM}(\mathrm{M})$. Then the sum $\mathrm{A}+\mathrm{B}$ of $\mathrm{A}$ and $\mathrm{B}$ is defined as

$\mu_{A+B}(x)=\left\{\begin{array}{cl}\mu_{A}(\mathrm{y}) \wedge \mu_{B}(\mathrm{z}) & ; \text { if } x=y+z \\ 0 & ; \text { otherwise }\end{array}\right.$ and $\quad v_{A+B}(x)=\left\{\begin{array}{cl}v_{A}(\mathrm{y}) \vee v_{B}(\mathrm{z}) & \text {; if } x=y+z \\ 1 & \text {; otherwise }\end{array}\right.$

Then, $\mathrm{A}+\mathrm{B} \in \operatorname{IFM}(\mathrm{M})$.

\section{Definition (2.5)}

Let $\mathrm{M}$ be an R-module and let $\mathrm{A} \in \operatorname{IFS}(\mathrm{R})$ and $\mathrm{B} \in \operatorname{IFM}(\mathrm{M})$. Then the product $\mathrm{AB}$ of $\mathrm{A}$ and $\mathrm{B}$ is defined as

$\mu_{A B}(x)=\left\{\begin{array}{cc}\mu_{A}(r) \wedge \mu_{B}(m) & \text {; if } x=r m \\ 0 & \text {; otherwise }\end{array}\right.$ and $v_{A B}(x)=\left\{\begin{array}{cc}v_{A}(r) \vee v_{B}(m) & \text {; if } x=r m \\ 1 & \text {; otherwise }\end{array}, r \in R, m \in M\right.$.

Clearly, $\mathrm{AB} \in \operatorname{IFM}(\mathrm{M})$.

\section{Definition (2.6) $[9,12]$}

Let $\mathrm{M}$ be an R-module and let $\mathrm{A}, \mathrm{B} \in \operatorname{IFM}(\mathrm{M})$. Then the product $\mathrm{AB}$ of $\mathrm{A}$ and $\mathrm{B}$ is defined as

$\mu_{A B}(x)=\left\{\begin{array}{cc}\mu_{A}(y) \wedge \mu_{B}(z) & ; \text { if } x=y z \\ 0 & ; \text { otherwise }\end{array}\right.$ and $v_{A B}(x)=\left\{\begin{array}{cc}v_{A}(y) \vee v_{B}(z) & \text {; if } x=y z \\ 1 & \text {; otherwise }\end{array}\right.$, where $y, z \in M$. 


\section{Definition (2.7) [3]}

An $P \in \operatorname{IFI}(R)$ is called an intuitionistic fuzzy prime ideal of $R$ if for any $A, B \in \operatorname{IFI}(R)$ the condition $\mathrm{AB} \subseteq \mathrm{P}$ implies that either $\mathrm{A} \subseteq \mathrm{P}$ or $\mathrm{B} \subseteq \mathrm{P}$.

\section{Definition (2.8)}

Let $\mathrm{X}$ be a non empty set and $\mathrm{A} \subset \mathrm{X}$. Then an intuitionistic fuzzy set $\chi_{A}=\left(\mu_{\chi_{A}}, v_{\chi_{A}}\right)$ is called an intuitionistic fuzzy characteristic function and is defined as $\mu_{\chi_{A}}(x)=\left\{\begin{array}{ll}1 & \text {; if } x \in A \\ 0 & \text {; if } x \notin A\end{array}\right.$ and $v_{\chi_{A}}(x)=\left\{\begin{array}{ll}0 & \text {; if } x \in A \\ 1 & \text {; if } x \notin A\end{array}\right.$.

\section{Definition (2.9)}

Let Mbe R-module and $\chi_{\theta}$ is an IFS on M defined as $\chi_{\theta}(x)=\left(\mu_{\chi_{\theta}}(x), \nu_{\chi_{\theta}}(x)\right)$,

where $\mu_{\chi_{\theta}}(x)=\left\{\begin{array}{ll}1 & \text {; if } x=\theta \\ 0 & \text {; if } x \neq \theta\end{array}\right.$ and $v_{\chi_{\theta}}(x)= \begin{cases}0 & \text {; if } x=\theta \\ 1 & \text {; if } x \neq \theta\end{cases}$

and $\chi_{0}$ and $\chi_{\mathrm{R}}$ are IFSs on $\mathrm{R}$ defined by

$$
\begin{aligned}
& \chi_{0}(r)=\left(\mu_{\chi_{0}}(r), v_{\chi_{0}}(r)\right) \text { and } \chi_{R}(r)=\left(\mu_{\chi_{R}}(r), v_{\chi_{R}}(r)\right) \text {, where } \\
& \mu_{\chi_{0}}(r)=\left\{\begin{array}{ll}
1 & ; \text { if } r=0 \\
0 & \text {; if } r \neq 0
\end{array} ; v_{\chi_{0}}(r)=\left\{\begin{array}{ll}
0 & ; \text { if } r=0 \\
1 & ; \text { if } r \neq 0
\end{array} \text { ind } \mu_{\chi_{R}}(r)=1 ; v_{\chi_{R}}(r)=0, \forall r \in R .\right.\right.
\end{aligned}
$$

\section{Theorem (2.10)}

Let $x \in \mathrm{R}$ and $\alpha, \beta \in(0,1]$ with $\alpha+\beta \leq 1$. Then $\left\langle x_{(\alpha, \beta)}\right\rangle=(\alpha, \beta)_{<x>}$, where $(\alpha, \beta)_{<x>}(y)=\left\{\begin{array}{cl}(\alpha, \beta) & ; \text { if } y \in<x> \\ (0,1) & ; \text { if } y \notin<x>\end{array}\right.$ is called the $(\alpha, \beta)-$ level(or cut set $)$ intuitionistic fuzzy ideal corresponding to $\langle x\rangle$.

Proof. Case(i) When $y \in<x>$ and let $y=x^{n}$, for some positive interget $n$, then

$$
\begin{aligned}
& \mu_{(\alpha, \beta)_{<x>}}(y)=\alpha=\mu_{x_{(\alpha, \beta)}}(x) \leq \mu_{x_{(\alpha, \beta)}}\left(x^{n}\right)=\mu_{x_{(\alpha, \beta)}}(y) \text { and } \\
& v_{(\alpha, \beta)_{<x>}}(y)=\beta=v_{x_{(\alpha, \beta)}}(x) \geq v_{x_{(\alpha, \beta)}}\left(x^{n}\right)=v_{x_{(\alpha, \beta)}}(y)
\end{aligned}
$$

Case(ii) When $y \notin\langle x\rangle$, then

$$
\mu_{(\alpha, \beta)_{<x>}}(y)=0=\mu_{x_{(\alpha, \beta)}}(y) \text { and } v_{(\alpha, \beta)_{<x>}}(y)=1=v_{x_{(\alpha, \beta)}}(y) \text {. }
$$

Thus in both the cases we find that $(\alpha, \beta)_{<x>} \subseteq x_{(\alpha, \beta)}$.

Now $<x_{(\alpha, \beta)}>=\cap\left\{A: A \in I F I(\mathrm{R})\right.$ such that $\left.x_{(\alpha, \beta)} \subseteq A\right\}$ implies that $(\alpha, \beta)_{<x>}=<x_{(\alpha, \beta)}>$.

\section{Residual quotient of intuitionistic fuzzy sets of ring and module}

Throughout the paper, $\mathrm{R}$ is a commutative ring with unity $1,1 \neq 0, \mathrm{M}$ is a unitary $\mathrm{R}$-module and $\theta$ is the zero element of $\mathrm{M}$. For a subset $\mathrm{X}$ of $\mathrm{M}$, recall that $<\mathrm{X}>$ denotes the submodules of $\mathrm{M}$ generated by $\mathrm{X}$. For any $x \in \mathrm{X}$, we let $\langle x\rangle$ denote the submodule of M generated by $\{x\}$.

For any submodule $\mathrm{N}$ of $\mathrm{M}$ we have $(\mathrm{N}: \mathrm{M})=\{r \mid r \in \mathrm{R}, \quad r \mathrm{M} \subseteq \mathrm{N}\}$. 
International Journal of Computer Science \& Information Technology (IJCSIT) Vol 9, No 4, August 2017

In this section, we introduce and study the notion of residual quotient of intuitionistic fuzzy subsets of ring and module.

\section{Definition (3.1)}

For $\mathrm{A}, \mathrm{B} \in \operatorname{IFS}(\mathrm{M})$ and $\mathrm{C} \in \operatorname{IFS}(\mathrm{R})$, define the residual quotient (A: B) and (A: C) as follows:

$(A: \mathrm{B})=\bigcup\{\mathrm{D}: \mathrm{D} \in \operatorname{IFS}(R)$ such that $D \cdot B \subseteq A\}$ and

$(A: \mathrm{C})=\bigcup\{\mathrm{E}: \mathrm{E} \in \operatorname{IFS}(M)$ such that $C \cdot E \subseteq A\}$

Clearly, (A: B) $\in \operatorname{IFS}(\mathrm{R})$ and $(\mathrm{A}: \mathrm{C}) \in \operatorname{IFS}(\mathrm{M})$.

\section{Theorem (3.2)}

For $\mathrm{A}, \mathrm{B} \in \mathrm{IFS}(\mathrm{M})$ and $\mathrm{C} \in \mathrm{IFS}(\mathrm{R})$. Then we have

(i) $(A: B)=\bigcup\left\{r_{(\alpha, \beta)}: r \in R, \alpha, \beta \in[0,1]\right.$ with $\alpha+\beta \leq 1$ such that $\left.r_{(\alpha, \beta)} \cdot B \subseteq A\right\}$ and

(ii) $(A: C)=\bigcup\left\{x_{(\alpha, \beta)}: x \in M, \alpha, \beta \in[0,1]\right.$ with $\alpha+\beta \leq 1$ such that $\left.\mathrm{C} \cdot x_{(\alpha, \beta)} \subseteq A\right\}$.

Proof. (i) We know that

$\left\{r_{(\alpha, \beta)}: r \in R, \alpha, \beta \in[0,1]\right.$ with $\alpha+\beta \leq 1$ such that $\left.r_{(\alpha, \beta)} \cdot B \subseteq A\right\} \in I F S(\mathrm{R})$

$\therefore \quad\left\{r_{(\alpha, \beta)}: r \in R, \alpha, \beta \in[0,1]\right.$ with $\alpha+\beta \leq 1 \mathrm{such}$ that $\left.r_{(\alpha, \beta)} \cdot B \subseteq A\right\}$

$\subseteq\{\mathrm{D}: \mathrm{D} \in \operatorname{IFS}(R)$ such that $\mathrm{D} \cdot \mathrm{B} \subseteq A\}$

$\Rightarrow \bigcup\left\{r_{(\alpha, \beta)}: r \in R, \alpha, \beta \in[0,1]\right.$ with $\alpha+\beta \leq 1$ such that $\left.r_{(\alpha, \beta)} \cdot B \subseteq A\right\}$

$$
\subseteq \bigcup\{\mathrm{D}: \mathrm{D} \in \operatorname{IFS}(R) \text { such that } \mathrm{D} \cdot \mathrm{B} \subseteq A\}=(A: B) \text {. }
$$

Let $\mathrm{D} \in \mathrm{IFS}(\mathrm{R})$ such that $\mathrm{D} \cdot \mathrm{B} \subseteq \mathrm{A}$.

Let $r \in \mathrm{R}$ and $\mathrm{D}(r)=(\alpha, \beta)$, i.e., $\mu_{D}(r)=\alpha$ and $v_{D}(r)=\beta$.

Now, $\left(r_{(\alpha, \beta)} B\right)(x)=\left(\mu_{r_{(\alpha, \beta)} B}(x), v_{r_{(\alpha, \beta)} B}(x)\right)$, where

$$
\begin{aligned}
\mu_{r_{(\alpha, \beta)} B}(x) & =\vee\left\{\mu_{r_{(\alpha, \beta)}}(s) \wedge \mu_{B}(y): s \in R, y \in M, s y=x\right\} \\
& \leq \vee\left\{\mu_{D}(r) \wedge \mu_{B}(y): y \in M, r y=x\right\}\left[\because \mu_{r_{(\alpha, \beta)}}(s) \leq \mu_{D}(r)=\alpha\right] \\
& =\vee\left\{\mu_{D}(s) \wedge \mu_{B}(y): s \in R, y \in M, s y=x\right\} \\
& =\mu_{D B}(x) \\
& \leq \mu_{A}(x)
\end{aligned}
$$

i.e., $\mu_{r_{(\alpha, \beta)} B}(x) \leq \mu_{A}(x), \forall x \in M$.

Similarly, we can show that $v_{r_{(\alpha, \beta)} B}(x) \geq v_{A}(x), \forall x \in M$. Thus, $r_{(\alpha, \beta)} B \subseteq A$.

So, $(\mathrm{A}: \mathrm{B}) \subseteq \bigcup\left\{r_{(\alpha, \beta)}: r \in R, \alpha, \beta \in[0,1]\right.$ with $\alpha+\beta \leq 1$ such that $\left.r_{(\alpha, \beta)} B \subseteq A\right\}$

Hence $(\mathrm{A}: \mathrm{B})=\bigcup\left\{r_{(\alpha, \beta)}: r \in R, \alpha, \beta \in[0,1]\right.$ with $\alpha+\beta \leq 1$ such that $\left.r_{(\alpha, \beta)} B \subseteq A\right\}$.

(ii) The proof is similar to (i). 
International Journal of Computer Science \& Information Technology (IJCSIT) Vol 9, No 4, August 2017

Theorem (3.3) For A, B $\in \operatorname{IFS(M)}$ and $C \in \operatorname{IFS}(\mathrm{R})$. Then we have

(i) $(\mathrm{A}: \mathrm{B}) \cdot \mathrm{B} \subseteq \mathrm{A}$;

(ii) $\mathrm{C} \cdot(\mathrm{A}: \mathrm{C}) \subseteq \mathrm{A}$;

(iii) $\mathrm{C} \cdot \mathrm{B} \subseteq \mathrm{A} \Leftrightarrow \mathrm{C} \subseteq(\mathrm{A}: \mathrm{B}) \Leftrightarrow \mathrm{B} \subseteq(\mathrm{A}: \mathrm{C})$.

Proof. (i) Now, $((\mathrm{A}: \mathrm{B}) \cdot \mathrm{B})(x)=\left(\mu_{(\mathrm{A}: \mathrm{B}) \cdot \mathrm{B}}(x), v_{(\mathrm{A}: \mathrm{B}) \mathrm{B}}(x)\right)$, where

$$
\begin{aligned}
\mu_{(\mathrm{A}: \mathrm{B}) \mathrm{B}}(x) & =\vee\left\{\mu_{(\mathrm{A}: \mathrm{B})}(r) \wedge \mu_{B}(y) \mid r \in R, y \in M, r y=x\right\} \\
& =\vee\left\{\vee\left\{\mu_{D}(r) \mid \mathrm{D} \in I F S(\mathrm{R}), \mathrm{D} \cdot \mathrm{B} \subseteq A\right\} \wedge \mu_{B}(y) \mid r \in R, y \in M, r y=x\right\} \\
& =\vee\left\{\mu_{D}(r) \wedge \mu_{B}(y) \mid \mathrm{D} \in I F S(\mathrm{R}), \mathrm{D} \cdot \mathrm{B} \subseteq A, y \in M, r y=x\right\} \\
& \leq \vee\left\{\mu_{D \cdot B}(r y) \mid \mathrm{D} \in I F S(\mathrm{R}), \mathrm{D} \cdot \mathrm{B} \subseteq A, y \in M, r y=x\right\} \\
& \leq \vee\left\{\mu_{A}(r y) \mid \quad y \in M, r y=x\right\} \\
& =\mu_{A}(x) .
\end{aligned}
$$

Thus, $\mu_{\text {(A:B):B }}(x) \leq \mu_{A}(x), \forall x \in M$.

Similarly, we can show that $v_{(\mathrm{A}: \mathrm{B}) \mathrm{B}}(x) \geq v_{A}(x), \forall x \in M$.

Hence $(\mathrm{A}: \mathrm{B}) \cdot \mathrm{B} \subseteq \mathrm{A}$.

(ii) The proof is similar to (i)

(iii) This is an immediate consequences of (i) and (ii).

\section{Theorem (3.4)}

For $\mathrm{A}_{\mathrm{i}}(\mathrm{i} \in \mathrm{J}), \mathrm{B} \in \operatorname{IFS}(\mathrm{M})$ and $\mathrm{C} \in \operatorname{IFS}(\mathrm{R})$. Then we have

(i) $\left(\bigcap_{i \in J} A_{i}\right): \mathrm{B}=\bigcap_{i \in J}\left(A_{i}: B\right) \quad$ (ii) $\left(\bigcap_{i \in J} A_{i}\right): \mathrm{C}=\bigcap_{i \in J}\left(A_{i}: C\right)$.

Proof .(i) $\left(\bigcap_{i \in J} A_{i}\right): \mathrm{B}=\bigcup\left\{\mathrm{D}: \mathrm{D} \in \operatorname{IFS}(R)\right.$ such that $\left.D \cdot B \subseteq \bigcap_{i \in J} A_{i}\right\}$

$$
=\bigcup\left\{\mathrm{D}: \mathrm{D} \in \operatorname{IFS}(R) \text { such that } D \cdot B \subseteq A_{i}, \forall i \in J\right\}
$$$$
=\bigcup\left\{\mathrm{D}: \mathrm{D} \in \operatorname{IFS}(R) \text { such that } D \subseteq\left(A_{i}: B\right), \forall i \in J\right\}
$$$$
=\bigcup\left\{\mathrm{D}: \mathrm{D} \in \operatorname{IFS}(R) \text { such that } D \subseteq \bigcap_{i \in J}\left(A_{i}: B\right)\right\}
$$$$
\subseteq \bigcap_{i \in J}\left(A_{i}: B\right) \text {. }
$$

Thus $\left(\bigcap_{i \in J} A_{i}\right): \mathrm{B} \subseteq \bigcap_{i \in J}\left(A_{i}: B\right)$.

By previous theorem, we have

$\left(\bigcap_{i \in J}\left(\mathrm{~A}_{i}: \mathrm{B}\right) \cdot \mathrm{B}\right)(x)=\left(\mu_{\bigcap_{i \in J}\left(\mathrm{~A}_{i}: \mathrm{B}\right) \cdot \mathrm{B}}(x), v_{\bigcap_{i \in J}\left(\mathrm{~A}_{i}: \mathrm{B}\right) \cdot \mathrm{B}}(x)\right)$, where 
International Journal of Computer Science \& Information Technology (IJCSIT) Vol 9, No 4, August 2017

$$
\begin{aligned}
& \mu_{\bigcap_{i \in J}\left(\mathrm{~A}_{i}: \mathrm{B}\right) \cdot \mathrm{B}}(x)=\vee\left\{\left(\bigcap_{i \in J} \mu_{\left(\mathrm{A}_{i}: \mathrm{B}\right)}(r)\right) \wedge \mu_{B}(y) \mid r \in R, y \in M, r y=x\right\} \\
& \leq \vee\left\{\hat{i \in J}_{i \in J}\left(\mu_{\left(\mathrm{A}_{i}: \mathrm{B}\right)}(r)\right) \wedge \mu_{B}(y) \mid r \in R, y \in M, r y=x\right\} \\
& \leq \vee\left\{\underset{i \in J}{\wedge}\left(\mu_{\left(\mathrm{A}_{i}: \mathrm{B}\right)}(r y)\right) \mid r \in R, y \in M, r y=x\right\} \\
& \leq \vee\left\{\hat{i \in J}_{\mathrm{A}_{i}} \mu_{\mathrm{\textrm {A }}}(r y) \mid r \in R, y \in M, r y=x\right\} \\
& =\mu_{\bigcap_{i \in I} \mathrm{~A}_{i}}(x)
\end{aligned}
$$

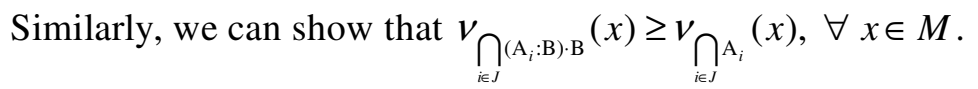

Thus, $\bigcap_{i \in J}\left(\mathrm{~A}_{i}: \mathrm{B}\right) \cdot \mathrm{B} \subseteq \bigcap_{i \in J} \mathrm{~A}_{i}$ and so $\bigcap_{i \in J}\left(\mathrm{~A}_{i}: \mathrm{B}\right) \subseteq\left(\bigcap_{i \in J} \mathrm{~A}_{i}\right): \mathrm{B}$

From (1) and (2) we get $\bigcap_{i \in J}\left(\mathrm{~A}_{i}: \mathrm{B}\right)=\left(\bigcap_{i \in J} \mathrm{~A}_{i}\right): \mathrm{B}$.

(ii) The proof is similar to (i).

\section{Theorem (3.5)}

For $\mathrm{A}, \mathrm{B} \in \operatorname{IFS}(\mathrm{M})$ and $\mathrm{C} \in \operatorname{IFS}(\mathrm{R})$

(i) If $\mathrm{A} \in \operatorname{IFM}(M)$, then $(\mathrm{A}: \mathrm{B})=\bigcup\{\mathrm{D}: \mathrm{D} \in I F I(R)$ such that $D \cdot B \subseteq A\}$

(ii) If $\mathrm{C} \in I F I(R)$, then $(\mathrm{A}: \mathrm{C})=\bigcup\{\mathrm{E}: \mathrm{E} \in I F M(\mathrm{M})$ such that $\mathrm{C} \cdot E \subseteq A\}$

Proof. (i) Clearly, $\{\mathrm{D}: \mathrm{D} \in \operatorname{IFI}(R)$ s.t $D \cdot B \subseteq A\} \subseteq \bigcup\{\mathrm{D}: \mathrm{D} \in \operatorname{IFS}(R)$ s.t $D \cdot B \subseteq A\}=(A: B)$.

Let $r \in R, \alpha, \beta \in(0,1]$ with $\alpha+\beta \leq 1$ such that $r_{(\alpha, \beta)} \cdot B \subseteq A$.

Let $D=<r_{(\alpha, \beta)}>$. Then $<r_{(\alpha, \beta)}>\cdot B=(\alpha, \beta)_{<r>} \cdot B$.

Again, $\mu_{(\alpha, \beta)_{<r>B} B}(x)=\vee\left\{\mu_{(\alpha, \beta)_{<r\rangle}}(s) \wedge \mu_{B}(y) \mid r \in R, y \in M, s y=x\right\}$

$$
\begin{aligned}
& =\vee\left\{\alpha \wedge \mu_{A}(y) \mid s \in<r>, y \in M, s y=x\right\} \\
& \leq \vee\left\{\mu_{r_{(\alpha, \beta) B}}(r y) \mid t \in R, y \in M, \mathrm{t}(r y)=x\right\} \\
& \leq \vee\left\{\mu_{A}(r y) \mid t \in R, y \in M, \mathrm{t}(r y)=x\right\} \\
& \leq \vee\left\{\mu_{A}(\mathrm{t}(r y)) \mid t \in R, y \in M, \mathrm{t}(r y)=x\right\} \\
& =\mu_{A}(x) .
\end{aligned}
$$

Thus, $\mu_{(\alpha, \beta)_{<r>} B}(x) \leq \mu_{A}(x)$. Similarly, we can show that $v_{(\alpha, \beta)_{<r\rangle} B}(x) \geq v_{A}(x), \forall x \in M$.

Therefore, we have $(\alpha, \beta)_{<r>} \cdot B \subseteq A$.

Hence $\bigcup\{\mathrm{D}: \mathrm{D} \in \operatorname{IFI}(R)$ such that $D \cdot B \subseteq A\} \supseteq(A: B)$

Hence $(A: B)=\bigcup\{\mathrm{D}: \mathrm{D} \in I F I(R)$ such that $D \cdot B \subseteq A\}$.

(ii) The proof is similar to (i). 
International Journal of Computer Science \& Information Technology (IJCSIT) Vol 9, No 4, August 2017

\section{Theorem (3.6)}

For $\mathrm{A} \in \operatorname{IFM}(\mathrm{M}), \mathrm{B} \in \operatorname{IFS}(\mathrm{M})$ and $\mathrm{C} \in \operatorname{IFI}(\mathrm{R})$. Then

(i) $(\mathrm{A}: \mathrm{B}) \in \operatorname{IFI}(\mathrm{R})$ and (ii) $(\mathrm{A}: \mathrm{C}) \in \operatorname{IFM}(\mathrm{M})$.

Proof. (i) Since $\chi_{0} A \subseteq \chi_{\theta} \subseteq A$, so $\chi_{0} \subseteq$ (A: B). Let $r_{1}, r_{2}, r, s \in R$ be any elements. Then,

$$
\begin{aligned}
& \mu_{(A: B)}\left(r_{1}\right) \wedge \mu_{(A: B)}\left(r_{2}\right) \\
& =\left(\vee\left\{\mu_{A_{1}}\left(r_{1}\right): A_{1} \in I F I(R), A_{1} A \subseteq B\right\}\right) \wedge\left(\vee\left\{\mu_{A_{2}}\left(r_{2}\right): A_{2} \in I F I(R), A_{2} A \subseteq B\right\}\right) \\
& =\vee\left\{\mu_{A_{1}}\left(r_{1}\right) \wedge \mu_{A_{2}}\left(r_{2}\right): A_{1}, A_{2} \in I F I(R), A_{1} A \subseteq B, A_{2} A \subseteq B\right\} \\
& \leq \vee\left\{\mu_{\left(A_{1}+A_{2}\right)}\left(r_{1}\right) \wedge \mu_{\left(A_{1}+A_{2}\right)}\left(r_{2}\right): A_{1}, A_{2} \in I F I(R), A_{1} A \subseteq B, A_{2} A \subseteq B\right\} \\
& \leq \vee\left\{\mu_{\left(A_{1}+A_{2}\right)}\left(r_{1}-r_{2}\right): A_{1}+A_{2} \in I F I(R), A_{1} A+A_{2} A \subseteq\left(A_{1}+A_{2}\right) A \subseteq B+B=B\right\} \\
& \leq \vee\left\{\mu_{D}\left(r_{1}-r_{2}\right): D \in I F I(R), D A \subseteq B\right\} \\
& =\mu_{(A: B)}\left(r_{1}-r_{2}\right) .
\end{aligned}
$$

Thus, $\mu_{(A: B)}\left(r_{1}-r_{2}\right) \geq \mu_{(A: B)}\left(r_{1}\right) \wedge \mu_{(A: B)}\left(r_{2}\right)$.

Similarly, we can show that $v_{(A: B)}\left(r_{1}-r_{2}\right) \leq v_{(A: B)}\left(r_{1}\right) \wedge v_{(A: B)}\left(r_{2}\right)$.

Again, $\mu_{(A: B)}(s r)=\vee\left\{\mu_{D}(s r): D \in I F I(R), D A \subseteq B\right\} \geq \vee\left\{\mu_{D}(r): D \in I F I(R), D A \subseteq B\right\}=\mu_{(A: B)}(r)$.

Thus, $\mu_{(A: B)}(s r) \geq \mu_{(A: B)}(r)$. Similarly, we can show that $v_{(A: B)}(s r) \leq v_{(A: B)}(r), \forall r, s \in R$.

Hence $(A: B) \in \operatorname{IFI}(R)$.

(ii) The proof is similar to (i).

Let $\mathrm{A}, \mathrm{B} \in \operatorname{IFM}(\mathrm{M})$ and $\mathrm{C} \in \operatorname{IFI}(\mathrm{R})$. Then $(\mathrm{A}: \mathrm{C})$ is called the residual quotient intuitionistic fuzzy submodule of $A$ and $C$ and $(A: B)$ is called the residual quotient intuitionistic fuzzy ideal of $\mathrm{A}$ and $\mathrm{B}$ respectively.

\section{Theorem (3.7)}

For $\mathrm{A}, \mathrm{B}_{\mathrm{i}} \in \operatorname{IFS}(\mathrm{M})$ and $\mathrm{C}_{\mathrm{i}} \in \mathrm{IFS}(\mathrm{R})$ for $\mathrm{i} \in \mathrm{J}$. Then we have

(i) $A:\left(\bigcup_{i \in J} B_{i}\right)=\bigcap_{i \in J}\left(A: B_{i}\right)$

(ii) $A:\left(\bigcup_{i \in J} C_{i}\right)=\bigcap_{i \in J}\left(A: C_{i}\right)$

Proof .(i) By definition (3.1)

$$
\begin{aligned}
A:\left(\bigcup_{i \in J} B_{i}\right) & =\bigcup\left\{\mathrm{D}: \mathrm{D} \in \operatorname{IFS}(R) \text { such that } D \cdot\left(\bigcup_{i \in J} B_{i}\right) \subseteq A\right\} \\
& =\bigcup\left\{\mathrm{D}: \mathrm{D} \in \operatorname{IFS}(R) \text { such that } \bigcup_{i \in J}\left(D: B_{i}\right) \subseteq A\right\} \\
& \subseteq \bigcup\left\{\mathrm{D}: \mathrm{D} \in I F S(R) \text { such that }\left(D: B_{i}\right) \subseteq A\right\}, \forall i \in J \\
& =\left(A: B_{i}\right), \forall i \in J .
\end{aligned}
$$

Therefore, $A:\left(\bigcup_{i \in J} B_{i}\right) \subseteq \bigcap_{i \in J}\left(A: B_{i}\right)$. 
International Journal of Computer Science \& Information Technology (IJCSIT) Vol 9, No 4, August 2017

By Theorem (3.3)

$\left(\bigcap_{i \in J}\left(A: B_{i}\right)\right) \cdot\left(\bigcup_{i \in J} B_{i}\right)=\bigcup_{j \in J}\left(\left(\bigcap_{i \in J}\left(A: B_{i}\right)\right) \cdot B_{j}\right) \subseteq \bigcup_{j \in J}\left(\left(A: B_{j}\right) \cdot B_{j}\right) \subseteq \bigcup_{j \in J} A=A$.

Thus $\bigcap_{i \in J}\left(A: B_{i}\right) \subseteq A:\left(\bigcup_{i \in J} B_{i}\right)$. Hence $A:\left(\bigcup_{i \in J} B_{i}\right)=\bigcap_{i \in J}\left(A: B_{i}\right)$.

\section{Lemma (3.8)}

Let $\mathrm{M}$ be a R-module, then $\left(\chi_{\theta}: \chi_{\theta}\right)=\chi_{R}$.

Proof. Since $\left(\chi_{\theta}: \chi_{\theta}\right)=\bigcup\left\{\mathrm{D}: \mathrm{D} \in \operatorname{IFS}(R)\right.$ such that $\left.D \cdot \chi_{\theta} \subseteq \chi_{\theta}\right\} \subseteq \chi_{R}$.

We claim that $\chi_{R} \subseteq\left(\chi_{\theta}: \chi_{\theta}\right)$. For this, we first show that $\chi_{R} \chi_{\theta}=\chi_{\theta}$.

Now, $\mu_{\chi_{R} \chi_{\theta}}(x)=\vee\left\{\chi_{R}(r) \wedge \chi_{\theta}(m): r \in R, m \in M, r m=x\right\}$ and

$v_{\chi_{R} \chi_{\theta}}(x)=\wedge\left\{\chi_{R}(r) \vee \chi_{\theta}(m): r \in R, m \in M, r m=x\right\}$.

Now, $\mu_{\chi_{R} \chi_{\theta}}(x)=\vee\left\{\chi_{R}(r) \wedge \chi_{\theta}(m): r \in R, m \in M, r m=x\right\}$

$$
\begin{aligned}
& =\vee\left\{\chi_{\theta}(m): r \in R, m \in M, r m=x\right\} \\
& =\left\{\begin{array}{lr}
1 ; \text { if } x=\theta \quad[\because \text { if } x=\theta \Rightarrow \text { one } m=\theta] \\
0 ; \text { if } x \neq \theta \quad[\because \text { if } x \neq \theta \Rightarrow m \neq \theta]
\end{array}\right.
\end{aligned}
$$

Also, $v_{\chi_{R} \chi_{\theta}}(x)=\wedge\left\{\chi_{R}(r) \vee \chi_{\theta}(m): r \in R, m \in M, r m=x\right\}$

$$
\begin{aligned}
& =\wedge\left\{\chi_{\theta}(m): r \in R, m \in M, r m=x\right\} \\
& =\left\{\begin{array}{ll}
0 & ; \text { if } x=\theta \\
1 & ; \text { if } x \neq \theta
\end{array} .\right.
\end{aligned}
$$

Thus, $\chi_{R} \chi_{\theta}(x)=\chi_{\theta}(x)$.

So, $\chi_{R} \subseteq \bigcup\left\{\mathrm{D}: \mathrm{D} \in \operatorname{IFS}(R), \mathrm{D} \chi_{\theta} \subseteq \chi_{\theta}\right\}=\left(\chi_{\theta}: \chi_{\theta}\right)$.

Hence $\left(\chi_{\theta}: \chi_{\theta}\right)=\chi_{R}$.

\section{Lemma (3.9)}

Let $\mathrm{M}$ be a R-module, then $\chi_{0} \subseteq\left(\chi_{\theta}: \mathrm{A}\right), \forall \mathrm{A} \in \operatorname{IFS}(M)$.

Proof. We show that $\chi_{0} A \subseteq \chi_{\theta} \forall \mathrm{A} \in \operatorname{IFS}(M)$.

Now, $\mu_{\chi_{0} A}(x)=\vee\left\{\mu_{\chi_{0}}(r) \wedge \mu_{A}(m): r \in R, m \in M, r m=x\right\}$

When $x \neq \theta \Rightarrow r \neq 0 ; \forall r \in R$, such that $r m=x$

$\Rightarrow \mu_{\chi_{0}}(r)=0 \forall r \in R$, such that $r m=x$. So, $\mu_{\chi_{0} A}(x)=0=\mu_{\chi_{\theta}}(x)$.

When $x=\theta \Rightarrow \mu_{\chi_{0} A}(\theta) \leq 1=\mu_{\chi_{\theta}}(\theta)$. Thus, $\mu_{\chi_{0} A}(x) \leq \mu_{\chi_{\theta}}(x)$.

Similarly, we can show that $v_{\chi_{0} A}(x) \geq v_{\chi_{\theta}}(x)$. Therefore, $\chi_{0} A \subseteq \chi_{\theta}$.

Hence $\chi_{0} \subseteq \bigcup\left\{\mathrm{D}: \mathrm{D} \in \operatorname{IFS}(R)\right.$ such that $\left.\mathrm{D} . \mathrm{A} \subseteq \chi_{\theta}\right\}=\left(\chi_{\theta}: A\right)$. 
International Journal of Computer Science \& Information Technology (IJCSIT) Vol 9, No 4, August 2017

\section{Lemma (3.10)}

Let $\mathrm{M}$ be a R-module and $\mathrm{A}, \mathrm{B} \in \mathrm{IFS}(\mathrm{M})$. If $\mathrm{A} \subseteq \mathrm{B}$, then $\left(\chi_{\theta}: B\right) \subseteq\left(\chi_{\theta}: A\right)$.

Proof. Let $\mathrm{A}, \mathrm{B} \in \operatorname{IFS}(\mathrm{M}), D \in \operatorname{IFS}(\mathrm{R})$. Then $D A(x)=\left(\mu_{D A}(x), v_{D A}(x)\right)$, where

$\mu_{D A}(x)=\vee\left\{\mu_{D}(r) \wedge \mu_{A}(m): r \in R, m \in M, r m=x\right\}$ and

$v_{D A}(x)=\wedge\left\{v_{D}(r) \vee v_{A}(m): r \in R, m \in M, r m=x\right\}$.

Now, $\mu_{D}(r) \wedge \mu_{A}(m) \leq \mu_{D}(r) \wedge \mu_{B}(m)$.

Therefore, $\mu_{D A}(x)=\vee\left\{\mu_{D}(r) \wedge \mu_{A}(m): r \in R, m \in M, r m=x\right\}$

$$
\begin{aligned}
& \leq \vee\left\{\mu_{D}(r) \wedge \mu_{B}(m): r \in R, m \in M, r m=x\right\} \\
& =\mu_{D B}(x) .
\end{aligned}
$$

Similarly, we can show that $v_{D A}(x) \geq v_{D B}(x)$. Thus $D A \subseteq D B$.

So, $D B \subseteq \chi_{\theta} \Rightarrow D A \subseteq \chi_{\theta}$.

$\therefore \bigcup\left\{D: D \in I F S(R)\right.$ such that $\left.D B \subseteq \chi_{\theta}\right\} \subseteq \bigcup\left\{D: D \in I F S(R)\right.$ such that $\left.D A \subseteq \chi_{\theta}\right\}$

$\Rightarrow\left(\chi_{\theta}: B\right) \subseteq\left(\chi_{\theta}: A\right)$.

\section{Theorem (3.11)}

Let $\mathrm{M}$ is a R-module and $\mathrm{A}, \mathrm{B} \in \operatorname{IFM}(\mathrm{M})$, then $\left(\chi_{\theta}: A+B\right)=\left(\chi_{\theta}: A\right) \cap\left(\chi_{\theta}: B\right)$.

Proof. Since A, B $\in \operatorname{IFM}(\mathrm{M}) \Rightarrow \mathrm{A}+\mathrm{B} \in \operatorname{IFM}(\mathrm{M})$, we have

$$
\begin{aligned}
& \mu_{A+B}(x)=\underset{x=y+z}{\vee}\left\{\mu_{A}(y) \wedge \mu_{B}(z)\right\} \geq \mu_{A}(x) \wedge \mu_{B}(\theta)=\mu_{A}(x) \text { and } \\
& v_{A+B}(x)=\underset{x=y+z}{\wedge}\left\{v_{A}(y) \vee v_{B}(z)\right\} \leq v_{A}(x) \vee v_{B}(\theta)=v_{A}(x), \forall x \in M .
\end{aligned}
$$

This implies that $A \subseteq A+B$ and $B \subseteq A+B$.

So, $\left(\chi_{\theta}: A+B\right) \subseteq\left(\chi_{\theta}: A\right)$ and $\left(\chi_{\theta}: A+B\right) \subseteq\left(\chi_{\theta}: B\right)$

$\Rightarrow\left(\chi_{\theta}: A+B\right) \subseteq\left(\chi_{\theta}: A\right) \cap\left(\chi_{\theta}: B\right)$.

Now, $\left(\chi_{\theta}: A\right) \cap\left(\chi_{\theta}: B\right)$

$=\left(\cup\left\{A_{1} \mid A_{1} \in \operatorname{IFI}(R), A_{1} A \subseteq \chi_{\theta}\right\}\right) \cap\left(\cup\left\{B_{1} \mid B_{1} \in \operatorname{IFI}(R), B_{1} B \subseteq \chi_{\theta}\right\}\right)$

$=\cup\left\{A_{1} \cap B_{1} \mid A_{1}, B_{1} \in I F I(R), A_{1} A \subseteq \chi_{\theta}, B_{1} B \subseteq \chi_{\theta}\right\}$

$\subseteq \cup\left\{C \mid C=A_{1} \cap B_{1} \in I F I(R), C A \subseteq \chi_{\theta}, \mathrm{C} B \subseteq \chi_{\theta}\right\}$

$\subseteq \cup\left\{C \mid C=A_{1} \cap B_{1} \in I F I(R), C(A+B) \subseteq C A+C B \subseteq \chi_{\theta}\right\}$

$=\cup\left\{C \mid C \in \operatorname{IFI}(R), C(A+B) \subseteq \chi_{\theta}\right\}$

$=\left(\chi_{\theta}: A+B\right)$.

Therefore, $\left(\chi_{\theta}: A\right) \cap\left(\chi_{\theta}: B\right) \subseteq\left(\chi_{\theta}: A+B\right)$.

Hence $\left(\chi_{\theta}: A+B\right)=\left(\chi_{\theta}: A\right) \cap\left(\chi_{\theta}: B\right)$. 
International Journal of Computer Science \& Information Technology (IJCSIT) Vol 9, No 4, August 2017

\section{Theorem (3.12)}

Let $\mathrm{M}$ is a R-module and $\mathrm{A}_{\mathrm{i}} \in \operatorname{IFM}(\mathrm{M}), \mathrm{i} \in \mathrm{J}$. Then $\left(\chi_{\theta}: \sum_{i \in J} A_{i}\right)=\bigcap_{i \in J}\left(\chi_{\theta}: A_{i}\right)$.

Proof. The proof is similar to above theorem (3.11).

\section{Annihilator of intuitionistic fuzzy subset of a ring and module}

In this section we study annihilator of intuitionistic fuzzy subset of rings and modules in term of residual quotient and investigate various characteristic of it.

Definition (4.1) Let $\mathrm{M}$ be a R-module and $\mathrm{A} \in \operatorname{IFS}(\mathrm{M})$, then the annihilator of $\mathrm{A}$ is denoted by ann(A) and is defined as: $\operatorname{ann}(A)=\bigcup\left\{\mathrm{B}: \mathrm{B} \in \operatorname{IFS}(R)\right.$ such that $\left.B A \subseteq \chi_{\theta}\right\}$.

Note that $\left(\chi_{\theta}: A\right)=\operatorname{ann}(A)$.

Lemma (4.2) Let M be a R-module, then $\operatorname{ann}\left(\chi_{\theta}\right)=\chi_{R}$.

Proof. The result follows from lemma (3.8) as $\operatorname{ann}\left(\chi_{\theta}\right)=\left(\chi_{\theta}: \chi_{\theta}\right)=\chi_{R}$.

Lemma (4.3) Let $\mathrm{M}$ be a R-module and $\mathrm{A} \in \operatorname{IFS}(\mathrm{M})$, then $\chi_{0} \subseteq \operatorname{ann}(A)$.

Proof. The result follows from lemma (3.9) as $\chi_{0} \subseteq\left(\chi_{\theta}: \mathrm{A}\right)=\operatorname{ann}(\mathrm{A})$.

Lemma (4.4) Let $\mathrm{M}$ be a R-module and $\mathrm{A}, \mathrm{B} \in \operatorname{IFS}(\mathrm{M})$. If $\mathrm{A} \subseteq \mathrm{B}$, then $\operatorname{ann}(B) \subseteq \operatorname{ann}(A)$.

Proof. The result follows from lemma (3.10). If $\mathrm{A} \subseteq \mathrm{B}$ then

$\operatorname{ann}(\mathrm{B})=\left(\chi_{\theta}: B\right) \subseteq\left(\chi_{\theta}: A\right)=\operatorname{ann}(\mathrm{A})$

Theorem (4.5) Let $\mathrm{M}$ be a R-module and $\mathrm{A} \in \operatorname{IFS}(\mathrm{M})$. Then

$\operatorname{ann}(A)=\bigcup\left\{r_{(\alpha, \beta)}: r \in R, \alpha, \beta \in[0,1]\right.$ with $\alpha+\beta \leq 1$ such that $\left.r_{(\alpha, \beta)} A \subseteq \chi_{\theta}\right\}$

Proof. The result follows from Theorem (3.2)

Theorem (4.6) Let $\mathrm{M}$ be a R-module and $\mathrm{A} \in \operatorname{IFS}(\mathrm{M})$. Then $\operatorname{ann}(\mathrm{A}) \mathrm{A} \subseteq \chi_{\theta}$.

Proof. Follows from Theorem (3.3) (i) by taking $\mathrm{A}=\chi_{\theta}$ and $\mathrm{B}=\mathrm{A}$.

Corollary (4.7) If $\mathrm{A} \in \operatorname{IFS}(\mathrm{M})$ be such that $\mu_{\mathrm{A}}(\theta)=1$ and $\mathrm{v}_{\mathrm{A}}(\theta)=0$, then $\operatorname{ann}(A) A=\chi_{\theta}$.

Proof. By Lemma (4.3) we have $\chi_{0} \subseteq \operatorname{ann}(A)$

$$
\begin{aligned}
& \Rightarrow \quad \mu_{\chi_{0}}(0) \leq \mu_{a n n(A)}(0) \text { and } v_{\chi_{0}}(0) \geq v_{a n n(A)}(0) \\
& \text { i.e., } \quad 1 \leq \mu_{a n n(A)}(0) \text { and } 0 \geq v_{a n n(A)}(0) \\
& \Rightarrow \quad \mu_{a n n(A)}(0)=1 \text { and } v_{a n n(A)}(0)=0 .
\end{aligned}
$$


Now, $\mu_{a n n(\mathrm{~A}) A}(\theta)=\vee\left\{\mu_{a n n(\mathrm{~A})}(r) \wedge \mu_{A}(m): r \in R, m \in M, r m=\theta\right\}$

$$
\begin{aligned}
& \geq \mu_{\text {ann(A) }}(0) \wedge \mu_{A}(\theta) \\
& =1 \wedge 1=1
\end{aligned}
$$

i.e., $\mu_{a n n(\mathrm{~A}) A}(\theta)=1$. Similarly, we can show that $v_{\operatorname{ann}(\mathrm{A}) A}(\theta)=0$.

Therefore, $\chi_{\theta} \subseteq \operatorname{ann}(A) A$. Hence by Theorem (4.6) we get

$\operatorname{ann}(\mathrm{A}) A=\chi_{\theta}$.

Note (4.8) If $A \in \operatorname{IFM}(M)$, then $\operatorname{ann}(A) A=\chi_{\theta}$.

Theorem (4.9) Let $M$ is a $R$-module and $B \in \operatorname{IFS}(R), A \in I F S(M)$ such that $B A \subseteq \chi_{\theta}$ if and only if $\mathrm{B} \subseteq \operatorname{ann}(\mathrm{A})$.

Proof. By definition of annihilator $\mathrm{BA} \subseteq \chi_{\theta} \Rightarrow \mathrm{B} \subseteq \operatorname{ann}(\mathrm{A})$.

Conversely, let $\mathrm{B} \subseteq$ ann $(\mathrm{A}) \Rightarrow \mathrm{BA} \subseteq \operatorname{ann}(\mathrm{A}) \mathrm{A} \subseteq \chi_{\theta}$.

Corollary (4.10) If in the above theorem (3.10) $\mu_{\mathrm{B}}(0)=1, \nu_{\mathrm{B}}(0)=0$ and $\mu_{\mathrm{A}}(\theta)=1, \nu_{\mathrm{A}}(\theta)=0$, then $\mathrm{BA}=\chi_{\theta}$ if and only if $\mathrm{B} \subseteq \operatorname{ann}(\mathrm{A})$.

Theorem (4.11) Let $M$ is a R-module and $A, B \in \operatorname{IFS}(M)$. Then the following conditions are equivalent:

(i) $\operatorname{ann}(B)=\operatorname{ann}(A)$, for all $B \subseteq A, \mathrm{~B} \neq \chi_{\theta}$.

(ii) $C B \subseteq \chi_{\theta}$ implies $C A \subseteq \chi_{\theta}$, for all $B \subseteq A, B \neq \chi_{\theta}, C \in \operatorname{IFS}(R)$.

Proof. For (i) $\Rightarrow$ (ii) Let $\mathrm{CB} \subseteq \chi_{\theta}$. Then by theorem (3.11) we have $\mathrm{C} \subseteq \operatorname{ann}(\mathrm{B})=\operatorname{ann}(\mathrm{A})$ (by (i)). Again by the same theorem we have $\mathrm{CA} \subseteq \chi_{\theta}$.

For (ii) $\Rightarrow$ (i) By theorem (4.6) we have ann(B)B $\subseteq \chi_{\theta}$.

So (ii) implies ann(B) $\mathrm{A} \subseteq \chi_{\theta}$ where $\mathrm{B} \subseteq \mathrm{A}, \mathrm{B} \neq \chi_{\theta}$.

By theorem (4.8) ann $(B) \subseteq \operatorname{ann}(A)$.

Also, $B \subseteq A \Rightarrow \operatorname{ann}(A) \subseteq \operatorname{ann}(B)$. Thus $\operatorname{ann}(A)=\operatorname{ann}(B)$.

Corollary (4.12) If in the above theorem $\mu_{A}(\theta)=1, v_{A}(\theta)=0$ and $\mu_{B}(\theta)=1, v_{B}(\theta)=0$. Then the above theorem can be stated as: The following conditions are equivalents:

(i) $\operatorname{ann}(B)=\operatorname{ann}(A)$, for all $B \subseteq A, \mathrm{~B} \neq \chi_{\theta}$.

(ii) $C B=\chi_{\theta}$ implies $C A=\chi_{\theta}$, for all $B \subseteq A, B \neq \chi_{\theta}, C \in I F S(R)$ with $\mu_{C}(0)=1, v_{C}(0)=0$.

Theorem (4.13) Let $\mathrm{M}$ is a R-module and $\mathrm{A} \in \mathrm{IFS}(\mathrm{M})$. Then $\operatorname{ann}(A)=\bigcup\left\{\mathrm{B}: \mathrm{B} \in \operatorname{IFI}(R)\right.$ such that $\left.B A \subseteq \chi_{\theta}\right\}$, where $\mathrm{IFI}(\mathrm{R})$ is the set of intuitionistic fuzzy ideals of $\mathrm{R}$.

Proof. It follows from Theorem (3.5)(i)

Theorem (4.14) Let $M$ is a R-module and $A \in \operatorname{IFS}(M)$. Then $\operatorname{ann}(A) \in \operatorname{IFI}(R)$.

Proof. It follows from Theorem (3.6) 
International Journal of Computer Science \& Information Technology (IJCSIT) Vol 9, No 4, August 2017

Theorem (4.15) Let $M$ is a R-module and $A_{i} \in \operatorname{IFS}(M), i \in \Lambda$. Then

$$
\operatorname{ann}\left(\bigcup_{i \in \Lambda} A_{i}\right)=\bigcap_{i \in \Lambda} \operatorname{ann}\left(A_{i}\right) \text {. }
$$

Proof. It follows from Theorem (3.7)(i)

Theorem (4.16) Let $M$ is a R-module and $A_{i} \in \operatorname{IFM}(M)$ for $i \in J$, then

$\operatorname{ann}\left(\sum_{i \in J} A_{i}\right)=\bigcap_{i \in J} \operatorname{ann}\left(A_{i}\right)$.

Proof. It follows from Theorem (3.12)

Definition (4.17) Let $M$ be R-module. Then $A \in \operatorname{IFS}(M)$ is said to be faithful if $\operatorname{ann}(A)=\chi_{0}$.

Lemma (4.18) Let $A \in \operatorname{IFS}(M)$ be faithful, where $M$ is $R$-module. If $R$ is non-zero then $\neq \chi_{\theta}$.

Proof. Since A is faithful $\Rightarrow \operatorname{ann}(A)=\chi_{0}$.

If $\mathrm{A}=\chi_{\theta}$ then $\operatorname{ann}(\mathrm{A})=\operatorname{ann}\left(\chi_{\theta}\right)=\chi_{\mathrm{R}}$. Thus we have $\chi_{0}=\chi_{\mathrm{R}} \Rightarrow \mathrm{R}=\{0\}$, a contradiction. Therefore, $\mathrm{A} \neq \chi_{\theta}$.

Theorem (4.19) Let $\mathrm{A} \in \mathrm{IFS}(\mathrm{R})$ with $\mu_{\mathrm{A}}(0)=1, v_{\mathrm{A}}(0)=0$. Then $\mathrm{A} \subseteq \operatorname{ann}(\operatorname{ann}(\mathrm{A}))$ and $\operatorname{ann}(\operatorname{ann}(\operatorname{ann}(\mathrm{A})))=\operatorname{ann}(\mathrm{A})$.

Proof. Let A be an intuitionistic fuzzy subset of R-module R. Then by corollary (4.7), we have $\operatorname{ann}(\mathrm{A}) \mathrm{A}=\chi_{0}$.

By theorem (4.9), we have $\mathrm{A} \subseteq \operatorname{ann}(\operatorname{ann}(\mathrm{A}))$

$\Rightarrow \quad \operatorname{ann}(\operatorname{ann}(\operatorname{ann}(\mathrm{A}))) \subseteq \operatorname{ann}(\mathrm{A}) \quad[$ using lemma (4.4) $]$

Again using (1) : $\operatorname{ann}(\mathrm{A}) \subseteq \operatorname{ann}(\operatorname{ann}(\operatorname{ann}(\mathrm{A})))$.

So, $\operatorname{ann}(\operatorname{ann}(\operatorname{ann}(\mathrm{A})))=\operatorname{ann}(\mathrm{A})$.

Theorem(3.20) Let $A \in \operatorname{IFS}(M)$. Then

$C_{(\alpha, \beta)}(\operatorname{ann}(A)) \subseteq \operatorname{ann}\left(C_{(\alpha, \beta)}(A)\right), \forall \alpha, \beta \in(0,1]$ with $\alpha+\beta \leq 1$.

Proof. Let $x \in C_{(\alpha, \beta)}(\operatorname{ann}(A))$. Then $\mu_{a n n(A)}(x) \geq \alpha>0$ and $v_{a n n(A)}(x) \leq \beta<1$

$\Rightarrow \vee\left\{\mu_{B}(x): B \in I F I(R), B A \subseteq \chi_{\theta}\right\} \geq \alpha$ and $\wedge\left\{v_{B}(x): B \in I F I(R), B A \subseteq \chi_{\theta}\right\} \leq \beta$

$\Rightarrow \mu_{B}(x) \geq \alpha$ and $v_{B}(x) \leq \beta$ for some $B \in \operatorname{IFI}(R)$ with $B A \subseteq \chi_{\theta}$.

If $x \notin \operatorname{ann}\left(C_{(\alpha, \beta)}(A)\right)$ then $\exists$ 's some $y \in C_{(\alpha, \beta)}(A)$ such that $x y \neq \theta$.

Now, $\mu_{B A}(x y) \geq \mu_{B}(x) \wedge \mu_{A}(y) \geq \alpha>0$ and $v_{B A}(x y) \leq v_{B}(x) \vee v_{A}(y) \leq \beta<1$,

which is a contradiction. Hence $C_{(\alpha, \beta)}(\operatorname{ann}(A)) \subseteq \operatorname{ann}\left(C_{(\alpha, \beta)}(A)\right)$.

Definition (4.21) $A \in \operatorname{IFI}(\mathrm{R})$ is said to be an intuitionistic fuzzy dense ideal if $\operatorname{ann}(\mathrm{A})=\chi_{0}$.

Definition (4.22) $A \in \operatorname{IFI}(\mathrm{R})$ is called intuitionistic fuzzy semiprime ideal of $\mathrm{R}$ if for any IFI B of $\mathrm{R}$ such that $\mathrm{B}^{2} \subseteq \mathrm{A}$ implies that $\mathrm{B} \subseteq \mathrm{A}$. 
Theorem (4.23) If $A$ is an IFI of a semi prime ring $\mathrm{R}$, then $\mathrm{A} \cap \operatorname{ann}(\mathrm{A})=\chi_{0}$ and $\mathrm{A}+\operatorname{ann}(\mathrm{A})$ is an intuitionistic fuzzy dense ideal of R.

Proof. Since $\mathrm{A} \cap \operatorname{ann}(\mathrm{A}) \subseteq \mathrm{A}, \mathrm{A} \cap \operatorname{ann}(\mathrm{A}) \subseteq \operatorname{ann}(\mathrm{A})$ so $(\mathrm{A} \cap \operatorname{ann}(\mathrm{A}))^{2} \subseteq \mathrm{A} \operatorname{ann}(\mathrm{A}) \subseteq \chi_{0}$. Now $R$ is a semiprime ring and it implies that 0 is a semiprime ideal of $R$ so $\chi_{0}$ is an intuitionistic fuzzy semi prime ideal of $\mathrm{R}$.

Also, $(\mathrm{A} \cap \operatorname{ann}(\mathrm{A}))^{2} \subseteq \chi_{0} \Rightarrow \mathrm{A} \cap \operatorname{ann}(\mathrm{A}) \subseteq \chi_{0}$ and hence $\mathrm{A} \cap \operatorname{ann}(\mathrm{A})=\chi_{0}$.

Hence $\operatorname{ann}(\mathrm{A}+\operatorname{ann}(\mathrm{A}))=\operatorname{ann}(\mathrm{A}) \cap \operatorname{ann}(\operatorname{ann}(\mathrm{A}))=\chi_{0}$ proving thereby $\mathrm{A}+\operatorname{ann}(\mathrm{A})$ is an intuitionistic fuzzy dense ideal of $R$.

Theorem (4.24) Let A be a non-zero intuitionistic fuzzy ideal of a prime ring $R$ with $\mu_{\mathrm{A}}(0)=1$, $v_{A}(0)=0$. Then $A$ is an intuitionistic fuzzy dense ideal of $R$.

Proof. Now, $A \operatorname{ann}(A)=\chi_{0} \Rightarrow \operatorname{ann}(A)=\chi_{0}$ or $A=\chi_{0}$. But $A \neq \chi_{0}$ so ann $(A)=\chi_{0}$. Hence $A$ is an intuitionistic fuzzy dense ideal of R.

Definition (4.25) If $A \in I F S(R)$. Then the intuitionistic fuzzy ideal of the form ann(A) is called an intuitionistic fuzzy ideal. Thus if $\mathrm{A}$ is an intuitionistic fuzzy annihilator ideal if and only if $\mathrm{A}$ $=\operatorname{ann}(\mathrm{B})$ for some $\mathrm{B} \in \mathrm{IFS}(\mathrm{R})$ with with $\mu_{\mathrm{B}}(0)=1, v_{\mathrm{B}}(0)=0$.

Remark (4.26) In view of theorem (4.19) it follows that $A$ is an annihilator ideal of $R$ implies $\operatorname{ann}(\operatorname{ann}(\mathrm{A}))=\mathrm{A}$.

Theorem (4.27) The annihilator ideals in a semiprime ring form a complete Boolean algebra with intersection as infimum and ann as complementation.

Proof. Since $\bigcap_{i \in I} \operatorname{ann}\left(A_{i}\right)=\operatorname{ann}\left(\sum_{i \in I} A_{i}\right)$, so any intersection of annihilator ideals is an intuitionistic fuzzy annihilator ideal. Hence these ideals form a complete semi-lattice with intersection as infimum. To show that they form a Boolean algebra it remain to show that: $\mathrm{A} \cap \operatorname{ann}(\mathrm{B})=\chi_{0}$ if and only if $\mathrm{A} \subseteq \mathrm{B}$, for any annihilator ideals $\mathrm{A}$ and $\mathrm{B}$.

If $\mathrm{A} \subseteq \mathrm{B}$ then $\mathrm{A} \cap \operatorname{ann}(\mathrm{B}) \subseteq \mathrm{B} \cap \operatorname{ann}(\mathrm{B})=\chi_{0}$.

Conversary, let $\mathrm{A} \cap \operatorname{ann}(\mathrm{B})=\chi_{0}$.

Now, $\mathrm{A} \operatorname{ann}(\mathrm{B}) \subseteq \mathrm{A} \cap \operatorname{ann}(\mathrm{B})=\chi_{0} \Rightarrow \mathrm{A} \subseteq \operatorname{ann}(\operatorname{ann}(\mathrm{B}))=\mathrm{B}$.

Theorem (4.28) Let $\mathrm{M}$ be a non-zero R-module. Suppose that there exist no ideal A maximal among the annihilators of non-zero intuitionistic fuzzy submodules (IFSMs) of M. Then A is an intuitionistic fuzzy prime ideal of R.

Proof. Since A is maximal among the annihilators of non-zero intuitionistic fuzzy submodules (IFSMs) of M. Therefore there is an IFSM B $\left(\neq \chi_{0}\right)$ of M such that $A=\operatorname{ann}(B)$.

Suppose $\mathrm{P}, \mathrm{Q} \in \mathrm{IFI}(\mathrm{R})$ properly containing $\mathrm{A}$ (i.e., $\mathrm{A} \subset \mathrm{P}$ and $\mathrm{A} \subset \mathrm{Q}$ ) such that $\mathrm{PQ} \subseteq \mathrm{A}$. If $\mathrm{QB}=\chi_{0}$ then $\mathrm{Q} \subseteq \operatorname{ann}(\mathrm{B})=\mathrm{A}$, which is a contradiction to our supposition so $\mathrm{QB} \neq \chi_{0}$. Now, $\mathrm{PQ} \subseteq \mathrm{A} \Rightarrow \mathrm{P}(\mathrm{QB}) \subseteq \mathrm{AB}=\operatorname{ann}(\mathrm{B}) \mathrm{B}=\mathrm{QB}=\chi_{0}$. So $\mathrm{Q} \subseteq \operatorname{ann}(\mathrm{QB})$.

Hence $\mathrm{A} \subseteq \operatorname{ann}(\mathrm{QB})$. This is a contradiction of the maximality of A. So A is an intuitionistic fuzzy prime ideal of R.

Remark (4.29) If $A \in \operatorname{IFM}(M), A \neq \chi_{\theta}$ satisfying one (hence both) the condition of Theorem (4.11) then $\mathrm{A}$ is called an intuitionistic fuzzy prime submodule of $\mathrm{M}$. 
Theorem (4.30) If $A$ is an intuitionistic fuzzy prime submodule of $M$ then ann(A) is an intuitionistic fuzzy prime ideal of R.

Proof. Let $\mathrm{A}$ be an intuitionistic fuzzy prime submodule of $\mathrm{M}$ and $\mathrm{PQ} \subseteq \operatorname{ann}(\mathrm{A})$, where $\mathrm{Q}$ is not contained in ann(A). Then $\chi_{\theta} \neq \mathrm{QA} \subseteq \mathrm{A}$. Now $\mathrm{PQ} \subseteq \operatorname{ann}(\mathrm{A}) \Rightarrow(\mathrm{PQ}) \mathrm{A} \subseteq \operatorname{ann}(\mathrm{A}) \mathrm{A}=\chi_{\theta}$. So, $\mathrm{P} \subseteq \operatorname{ann}(\mathrm{QA})=\operatorname{ann}(\mathrm{A})$, as $\mathrm{A}$ is prime. Hence $\operatorname{ann}(\mathrm{A})$ is prime ideal of $\mathrm{R}$.

\section{CONCLUSIONS}

In this paper we have developed the concept of residual quotient of intuitionistic fuzzy subset of rings and modules and then study some results on annihilator of an intuitionistic fuzzy subset of a R-module. Using this notion, we investigate some important characterization of intuitionistic fuzzy annihilator of subsets of modules. The annihilator of union (sum) of intuitionistic fuzzy submodules are obtained. Annihilator of intuitionistic fuzzy ideal of prime ring, semi prime ring are also obtained. Using the concept of intuitionistic fuzzy annihilators, intuitionistic fuzzy prime submodules and intuitionistic fuzzy ideals are defined and various related properties are established.

\section{ACKNOWLEDGEMENTS}

The second author would like to thank IKG PT University, Jalandhar for providing the opportunity to do research work.

\section{REFERENCES}

[1] K. T. Atanassov,(1986), Intuitionistic fuzzy sets, Fuzzy Sets and Systems, Vol. 20, No. 1, pp., 8796.

[2] K. T. Atanassov, (1999), Fuzzy sets, Theory and Applications, Studies in fuzziness and soft computing, 35, Physica-Verlag, Heidelberg.

[3] I. Bakhadach , S. Melliani, M. Oukessou and S.L. Chadli,(2016), Intuitionistic fuzzy ideal and intuitionistic fuzzy prime ideal in a ring, Notes on Intuitionistic Fuzzy Sets, Vol. 22, no. 2 pp 59-63.

[4] D.K. Basnet,(2011), Topic in intuitionistic fuzzy algebra, Lambert Academic Publishing, ISBN : 978 3-8443-9147-3.

[5] R. Biswas, (1989), Intuitionistic fuzzy subgroups, Math. Forum, Vol. 10, pp 37-46.

[6] E. Bland Paul, (2011), Rings and their modules, published by the Deutsche National Bibliothek, Germany ISBN: 978-3-11-025022-0.

[7] B. Davvaz, W.A. Dudek, Y.B. Jun,(2006), Intuitionistic fuzzy Hv-submodules, Information Sciences, Vol. 176, pp 285-300.

[8] K. Hur, H.K. Kang and H.K. Song, (2003), Intuitionistic fuzzy subgroup and subrings, Honam Math J. Vol. 25, No. 1, pp 19-41.

[9] P. Isaac, P.P. John, (2011), On intuitionistic fuzzy submodules of a module, Int. J. of Mathematical Sciences and Applications, Vol. 1, No. 3, pp 1447-1454.

[10] D. S. Malik and J. N. Mordeson, (1998), Fuzzy Commutative Algebra, World Scientific Publishing Co-Pvt. Ltd.

[11] K. Meena and K. V. Thomas, (2011), Intuitionistic L-Fuzzy Subrings, International Mathematical Forum, Vol. 6, No. 52, pp $2561-2572$.

[12] P.K. Sharma, (2011), ( $\alpha, \beta)$-Cut of Intuitionistic fuzzy modules- II, International Journal of Mathematical Sciences and Applications, Vol. 3 , No. 1, pp. 11-17.

[13] P. K. Sharma and Gagandeep Kaur, (2016), Intuitionistic fuzzy superfluous modules, Notes on Intuitionistic Fuzzy Sets, Vol. 22, No. 3, pp 34-46.

[14] S. Rahman, H.K. Sailia, (2012), Some aspects of Atanassov's intuitionistic fuzzy submodules, Int. J. Pure and Appl. Mathematics, Vol. 77, No. 3, pp 369-383.

[15] H.K. Saikia and M.C. Kalita, (2009), On Annihilator of fuzzy subsets of modules, Internal Journal of Algebra Vol. 3, No. 10, pp. 483- 488.

[16] L. A. Zadeh, (1965), Fuzzy sets, Information and Control, Vol. 8, pp 338-353. 
International Journal of Computer Science \& Information Technology (IJCSIT) Vol 9, No 4, August 2017

\section{Authors}

Dr. P.K. Sharma, Ph.D. is Associate Professor in Mathematics at D.A.V. College, Jalandhar, Punjab, India. Having a teaching experience of 24 years. His area of research include Fuzzy Algebra, Fuzzy Topology, Fuzzy Graph Theory, Intuitionistic fuzzy mathematics. Till date he has published 100 research papers in reputed National and International Journals. He has written four post-Graduate books on Algebra, Topology, Real Analysis and Discrete Mathematics.

Ms. Gagandeep Kaur, presently p ursing Ph.D from IKGPTU, Jalandhar, Punjab, India. She has a teaching experience of 4 years in CT group of Institutes, Shahpur, Jalandhar as Assistant professor in Mathematics.

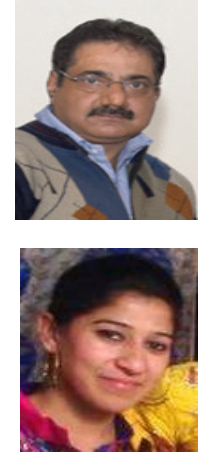

